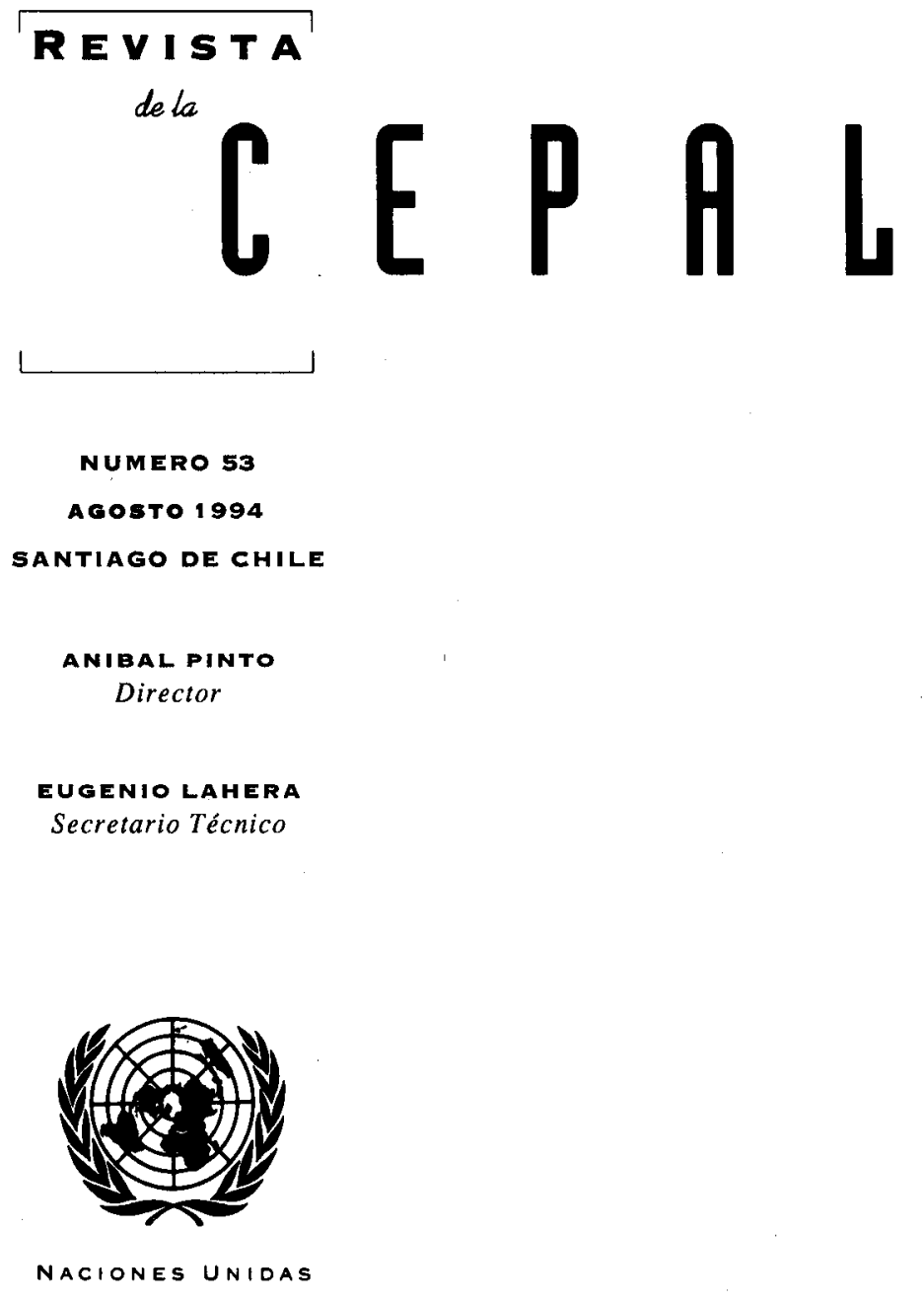


América Latina y el Caribe frente a la economía mundial

Gert Rosenthal

Afluencia de capitales externos y políticas macroeconómicas

Andras Uthoff y Daniel Titelman

Represión fínanciera y patrón de financiamlento latínoamericano

31

Marcos Antonio Macedo Cintra

Políticas de competitividad

49

Wilson Peres

Política industrial y fomento de la competitividad

Osvaldo Rosales

El regionalismo abierto y la integración económica

Juan A. Fuentes $K$.

Transformaciones del trabajo femenino urbano

91

Irma Arriagada

La gestión del agua y las cuencas en América Latina

Axel Dourojeanni

Políticas públicas y competitividad de las exportaciones

agrícolas

Milton von Hesse

Agroindustria y transformación productiva de la pequeña agricultura

Alejandro Schejtman

Grupos privados nacionales en México, 1988-1993

Celso Garrido

Evolución y perspectivas de la reforma y la apertura en China 


\section{Agroindustria y transformación productiva de la pequeña agricultura}

\section{Alexander Schejtman}

Economista Agrario, FAO.

La extensión del progreso tecnológico a los pequeños productores agrícolas es uno de los temas ineludibles de toda estrategia de transformación productiva con equidad en el ámbito rural. Con algunas excepciones, el balance de las políticas públicas en esta materia indica que éstas han distado mucho de cumplir con sus objetivos aun en períodos en que la restricción del gasto público no era la que hoy enfrentan las economías de la región. Una opción insuficientemente explorada ha sido la de involucrar a la agroindustria en la tarea de incorporar al progreso tecnológico a los pequeños productores susceptibles de convertirse en proveedores de materia prima, pese a que a juzgar por ciertas experiencias espontáneas existirían algunas formas de articulación capaces de elevar los niveles de producción y productividad de la pequeña agricultura. En este artículo se intenta fundamentar la necesidad de establecer una política de estímulo a la agroindustria para que cumpla el papel de difusora del progreso técnico en el sector de los pequeños productores y se formulan algunos lineamientos rectores para el diseño de dicha política. 


\section{I}

\section{Introducción}

En el presente artículo se intenta ampliar el alcance de los planteamientos formulados tanto por la $\mathrm{CEPAL}^{1}$ como por la $\mathrm{FAO}^{2}$ en relación con la necesidad de promover un proceso de transformación en el sector de la agricultura familiar.

Cabe advertir, sin embargo, que el artículo se limita a explorar los vínculos entre la agroindustria y aquel segmento de la agricultura familiar que, por la magnitud o calidad de los recursos de que dispone o puede llegar a disponer, tiene un potencial de desarrollo que podría materializarse a partir del establecimiento de esos nexos.
La articulación entre las unidades familiares con potencial de desarrollo y la agroindustria es sólo una de las formas que deberían adquirir los vínculos sectoriales en un proceso de revalorización del espacio rural. Otras formas complementarias de articulación, sobre todo para los campesinos sin tierra o con poca tierra, serían la creación de opciones de empleo en las industrias rurales no agrícolas, basadas en la difusión de tecnologías de especialización flexible y la organización de unidades productoras de infraestructura local (caminos, escuelas, centros de salud, viviendas, y otros)

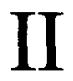

\section{Crecimiento con equidad: un objetivo consensual}

El crecimiento económico y la equidad constituyen objetivos consensuales de toda estrategia económica, cualesquiera sean las preferencias ideológicas de quienes la postulan y las características del país en desarrollo para el cual se formula. Cabe preguntarse, entonces, en qué medida se han alcanzado dichos objetivos en los países de América Latina.

En el estudio realizado por F. Fajnzylber (1989) que sirvió de inspiración a la propuesta de la CEPAL (CEPAL, 1990), se establece que en la región, en el período 1965-1985, algunos países habrían logrado un grado razonable de equidad, pero con ritmos de crecimiento económico reducidos (Argentina y Uruguay); otros, lograron grados aceptables de dinamismo pero con alta inequidad en la distribución del ingreso (Brasil, México, Colombia, Ecuador), y finalmente, otros no lograron ni crecimiento ni equidad (Bolivia, Chile, Perú, Haití y los países de Centroamérica).

1 Véase CEPAL, 1990, en particular las páginas 134 a 138, documento presentado al Vigésimotercer Período de Sesiones de la CEPAL, Caracas, Venezuela, 3 al 11 mayo, 1990.

2 Véase FAO, 1988, documento presentado en la $19^{\text {a }}$ Conferencia Regional de la FAO para América Latina y el Caribe, Barbados, 5 al 13 agosto 1986 .
El hecho de que no existan en la región ejemplos de países que hayan alcanzado crecimiento con equidad no significa que ello sea consustancial a su condición de países de industrialización tardía, pues un número importante de países de otros continentes, que exhiben la misma condición, como Taiwán, Corea, Portugal, Tailandia, Indonesia, China, Sri Lanka, lograron ambos resultados en el período considerado. Por otra parte, se trata de países que muestran la mayor diversidad en cuanto a tamaño, instituciones y cultura, lo que de plano elimina como factores explicativos únicos a algunos de los derivados de dichas características.

En el estudio citado, Fajnzylber presenta en detalle las diferencias más relevantes en el funcionamiento de la economía que existen entre los países que lograron crecimiento con equidad y los países de la región. En síntesis, allí se señala que el primer grupo de países se habría caracterizado por: i) la adopción de patrones de consumo más austeros; ii) una mayor contribución del ahorro interno; iii) el uso de dicho ahorro para la formación de capital; iv) un menor peso de la inversión extranjera; v) un mayor énfasis en la formación de capital humano; vi) un mayor esfuerzo en investigación y desarrollo con alta participación del sector privado y vii) el desarrollo de 
líneas de producción caracterizadas por un progresivo mayor contenido tecnológico de los productos generados, que permitieron una inserción más dinámica en el comercio exterior.

Nuestra hipótesis es que, más allá de las diferencias señaladas, existe otra que, a nuestro juicio, está en el origen mismo de la gestación de los círculos virtuosos que facilitaron la difusión del progreso tecnológico y permitieron un crecimiento equitativo. Se trata de la existencia de estructuras agrarias relativamente homogéneas en las fases iniciales de la industrialización, como lo muestra la experiencia histórica de los países que alcanzaron dicha condición.

En efecto, las estructuras agrarias formadas por una masa relativamente homogénea de pequeños y medianos productores constituyeron un mercado para la producción masiva de bienes simples de consumo y de producción que, en las fases iniciales de la industrialización, dio lugar al surgimiento interno de empresas destinadas a satisfacerlo; el desarrollo de estas últimas, a su vez, generó una demanda cada vez mayor de alimentos e insumos agrícolas configurando, de este modo, una verdadera espiral de demanda recíproca que permitió una creciente sofisticación de los patrones de consumo y de las técnicas de producción. Las técnicas así desarrolladas, por tratarse de estructuras agrarias homogéneas, resultaron válidas para la gran mayoría de los productores.

Esta dinámica contrasta con la experimentada por las economías cuyas estructuras agrarias se consolidaron en torno a la hacienda o la plantación. En ellas, la demanda tanto de bienes de consumo como de inversión mostró tempranamente una marcada polarización, en que los componentes del consumo de las elites y los medios de producción que caracterizaron el proceso de transición del latifundio hacia la gran empresa agrícola moderna se volcaron hacia el exterior.

Como resultado de este proceso de transición, las estructuras agrarias de la mayoría de los países de la región responden hoy a un patrón que, simplificando, puede calificarse como bimodal $^{3}$ pues presenta un segmento de empresas capitalistas con distinto grado de modernización y otro de unidades campesinas diferenciadas. Esta situación se da incluso en aquellos países que experimentaron reformas agrarias de cualquier intensidad.

\section{III}

\section{La bimodalidad agraria y sus implicaciones}

La existencia de estructuras bimodales (gráfico 1) plantea problemas complejos que entorpecen la amplia difusión del progreso tecnológico — definida aquí como una de las condiciones más importantes para alcanzar un crecimiento con equidad - pues mientras en las estructuras homogéneas una opción tecnológica válida (es decir, coherente con la dotación relativa de recursos de la economía) lo es para la gran mayoría de las unidades productivas, en las estructuras bimodales, una opción válida para la gran empresa agrícola moderna es improbable que lo sea también para el sector de la agricultura familiar, para un conjunto dado de precios relativos.

En un contexto como el señalado, de acuerdo con los datos empíricos disponibles y un cierto fundamento teórico, existirían notables diferencias en uno y otro tipo de agricultura en los criterios que

3 Para una mejor comprensión de este concepto véase Johnston y Kilby, 1975. orientan las decisiones respecto a qué producir, cuánto, cómo y para qué, decisiones que son de gran importancia para el diseño de la estrategia de desarrollo del sector. Sintetizando, esas diferencias derivan, fundamentalmente, del hecho de que la unidad familiar es a la vez una unidad de producción, consumo y reproducción, en que la actividad doméstica es inseparable de la actividad productiva y en que esta última se realiza sin recurrir a fuerza de trabajo asalariada, salvo de modo ocasional o en magnitudes poco significativas respecto al peso de la mano de obra familiar. Estas características determinan las diferencias que existen en una serie de atributos, importantes desde el punto de vista de su comportamiento, entre la agricultura campesina y la empresarial (cuadro 1$)^{4}$.

Si las consideraciones anteriores șon válidas, un

\footnotetext{
4 Para un análisis detallado de cada uno de los atributos considerados véase Schejtman, 1980, pp. 123 a 133.
} 


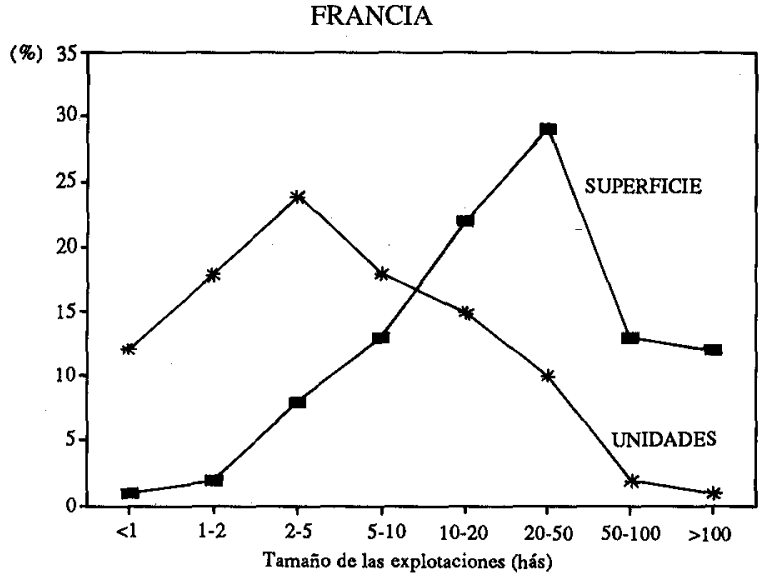

BOLIVIA

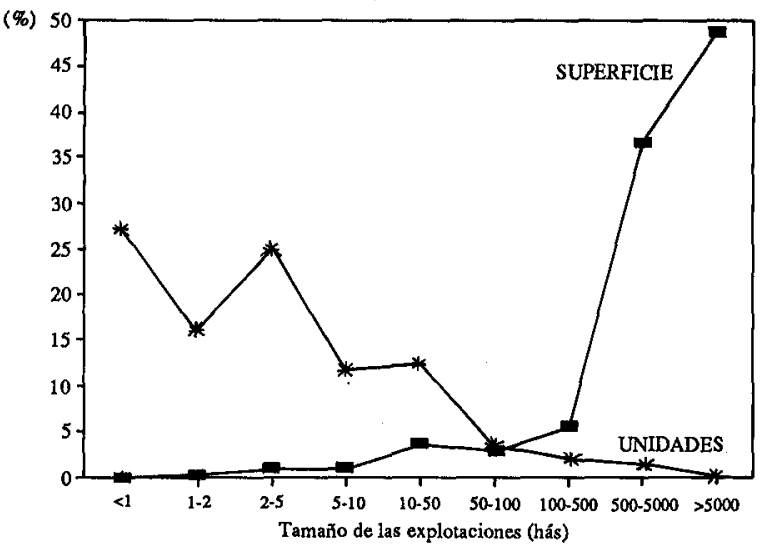

conjunto dado de señales de mercado, en un marco de equilibrios macroeconómicos razonables, que resulta relativamente válido para orientar el comportamiento del sector empresarial moderno, será a todas luces insuficiente para inducir un proceso de transformación en el sector de los pequeños productores.

La necesidad de formular políticas o estrategias diferenciadas por tipo de productor ha sido explícita o implícitamente reconocida en las propuestas de los organismos internacionales de financiamiento y asistencia técnica, así como también por los centros o institutos nacionales de desarrollo rural y por los organismos no gubernamentales orientados al sector de la pequeña producción; sin embargo, el número de experiencias frustradas ha sido mayor que el de los ejemplos exitosos. Entre los factores que explican esta

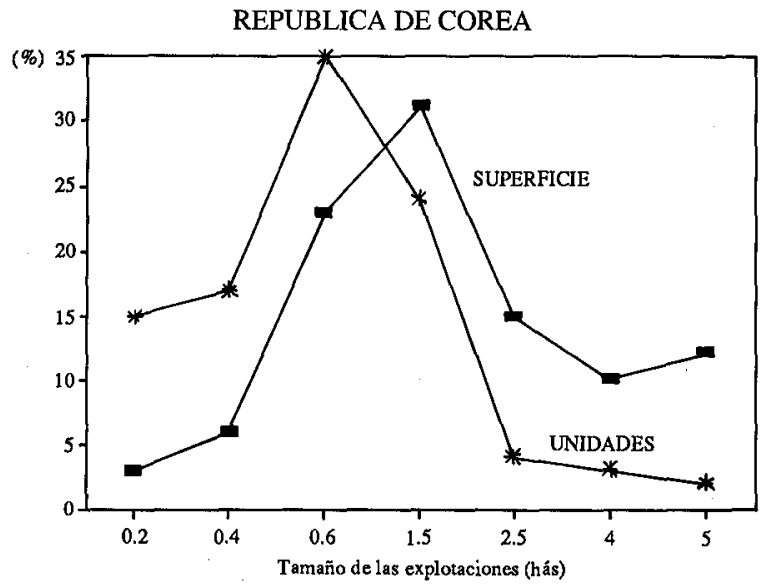

COLOMBIA

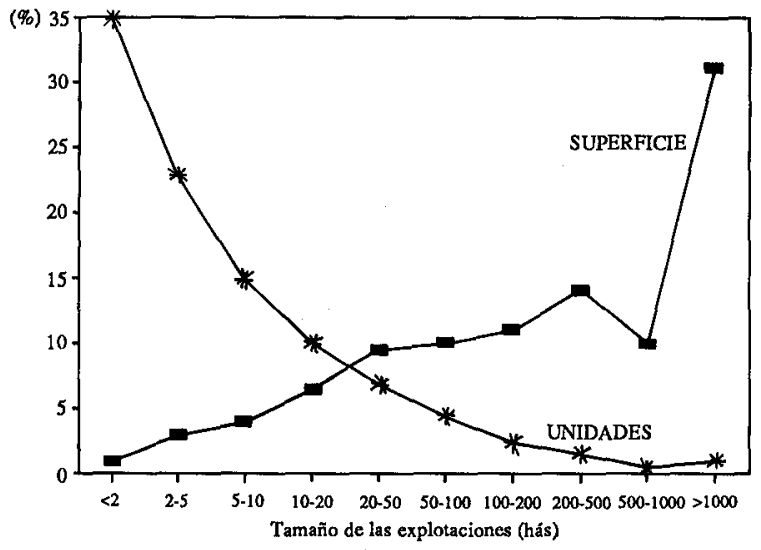

falta de éxito se pueden mencionar, entre otros, un entorno económico y socio-institucional adverso; la incomprensión de la lógica interna de manejo de las unidades familiares; la heterogeneidad de las unidades que se incluyen en los proyectos de desarrollo; la opción de rescatar tecnologías tradicionales de baja productividad, en una peculiar interpretación de 10 "adecuado"; una concepción asistencialista de la política respecto a este sector de productores, y una sectorialización estrecha de las medidas de política, lo que inhibe el aprovechamiento del potencial implícito en el fortalecimiento de los vínculos sectoriales.

Precisamente este último aspecto servirá de punto de partida a las observaciones sobre el papel potencial de la agroindustria que se formulan en los párrafos siguientes. 
CUADRO 1

\section{Características diferenciales de la agricultura campesina y de la empresarial}

\begin{tabular}{|c|c|c|}
\hline Atributos & Agricultura campesina & Agricultura empresarial \\
\hline $\begin{array}{l}\text { Objetivo de } \\
\text { la producción }\end{array}$ & $\begin{array}{l}\text { Reproducción de la familia } \\
\text { y de la unidad de producción }\end{array}$ & $\begin{array}{l}\text { Maximizar la tasa de } \\
\text { ganancia y la acumulación de capital }\end{array}$ \\
\hline $\begin{array}{l}\text { Origen de la } \\
\text { fuerza de } \\
\text { trabajo }\end{array}$ & $\begin{array}{l}\text { Fundamentalmente familiar y, } \\
\text { en ocasiones, intercambio } \\
\text { recíproco con otras unidades; } \\
\text { excepcionalmente asalariada } \\
\text { en cantidades marginales }\end{array}$ & Asalariada \\
\hline $\begin{array}{l}\text { Compromiso laboral del } \\
\text { jefe con la mano de obra }\end{array}$ & Absoluto & $\begin{array}{l}\text { Inexistente, salvo por } \\
\text { obligación legal }\end{array}$ \\
\hline Tecnología & $\begin{array}{l}\text { Alta intensidad de mano de } \\
\text { obra, baja densidad de } \\
\text { "capital" y de insumos } \\
\text { comprados por jornada } \\
\text { de trabajo }\end{array}$ & $\begin{array}{l}\text { Mayor densidad de capital } \\
\text { por activo y mayor } \\
\text { proporción de insumos } \\
\text { comprados en el valor del } \\
\text { producto final. }\end{array}$ \\
\hline $\begin{array}{l}\text { Destino del producto y } \\
\text { origen de los insumos }\end{array}$ & Parcialmente mercantil & Mercantil \\
\hline $\begin{array}{l}\text { Criterio de } \\
\text { intensificación de trabajo }\end{array}$ & $\begin{array}{l}\text { Máximo producto total, aun a costa del } \\
\text { descenso del producto medio. } \\
\text { Límite: producto marginal cero }\end{array}$ & $\begin{array}{l}\text { Productividad marginal > } \\
\text { que el salario }\end{array}$ \\
\hline $\begin{array}{l}\text { Riesgo e } \\
\text { incertidumbre }\end{array}$ & $\begin{array}{l}\text { Evasión no probabilística: } \\
\text { "algoritmo de sobrevivencia" }\end{array}$ & $\begin{array}{l}\text { Internalización probabilística buscando } \\
\text { tasas de ganancia proporcionales al riesgo }\end{array}$ \\
\hline $\begin{array}{l}\text { Carácter de } \\
\text { la fuerza de trabajo }\end{array}$ & $\begin{array}{l}\text { Fuerza valorizada de } \\
\text { trabajo intransferible o marginal }\end{array}$ & $\begin{array}{l}\text { Sólo emplea fuerza de trabajo transferible en } \\
\text { función de calificación }\end{array}$ \\
\hline $\begin{array}{l}\text { Componentes del ingreso o } \\
\text { producto neto }\end{array}$ & $\begin{array}{l}\text { Producto o ingreso familiar indivisibles } \\
\text { y realizados parcialmente en especie }\end{array}$ & $\begin{array}{l}\text { Salario, renta y ganancias } \\
\text { exclusivamente pecuniarias }\end{array}$ \\
\hline
\end{tabular}

\section{IV}

\section{Agroindustria y agricultura familiar}

Una primera característica general de la agroindustria es su mayor capacidad comparativa de "arrastre" respecto a otros sectores, es decir, su mayor capacidad de generar efectos directos e indirectos por unidad de demanda final agroindustrial (cuadro 2). En efecto, sin perjuicio de las diferencias que presenta la estructura productiva de los países considerados, en todos ellos, el incremento de la demanda final de productos agroalimentarios genera un mayor nivel de producción derivada, en el conjunto de los sectores productores de bienes, que la que caracterizaría al resto de dichos sectores. Además, al comparar los efectos de dicha demanda derivada en los componentes del valor agregado se advierte que tienen un significativo mayor impacto en el empleo, y una importante menor incidencia en el uso de insumos importados, aunque sus efectos en las remuneraciones sean menores que los de otros sectores (cuadro 3 ).

A su capacidad inductora, la producción agroalimentaria agrega otros atributos frecuentemente reconocidos, como por ejemplo, su capacidad de: reducir la perecibilidad de los productos y las pérdidas poscosecha; reducir la estacionalidad de la oferta; elevar el valor agregado del producto primario; satisfacer 
los patrones urbanos de demanda; enriquecer el valor nutritivo de los insumos agrícolas y cambiar sus características organolépticas.

Sin embargo, la agroindustria presenta algunas características, no suficientemente reconocidas, que la hacen especialmente valiosa para fortalecer la agricultura familiar. Estas son: i) mayor flexibilidad relativa en materia de escalas eficientes que muchas otras industrias; esto permite que su dimensionamiento mantenga cierta proporcionalidad con el tamaño y los recursos de las localidades de desarrollo rural con las cuales se plantea su articulación; ${ }^{5}$ ii) permite la integración de procesos de alta densidad de capital (por unidad de empleo generado) con procesos absorbedo-
CUADRO 2

América Latina (cinco países): Indices de eslabonamiento "hacia atrás" por unidad de demanda final al sector agroalimentarioa

\begin{tabular}{lcccc}
\hline & Agricultura & $\begin{array}{c}\text { Industria } \\
\text { alimentaria }\end{array}$ & $\begin{array}{c}\text { Sector } \\
\text { alimentario }\end{array}$ & $\begin{array}{c}\text { Resto de } \\
\text { sectores }\end{array}$ \\
\hline brasil & 0.9063 & 1.2865 & 1.1947 & 1.0981 \\
Chile & 0.9702 & 1.2230 & 1.1555 & 0.9897 \\
Guatemala & 0.9263 & 1.3429 & 1.1039 & 1.0013 \\
Haití & 0.8372 & 1.2833 & 1.0393 & 0.9891 \\
México & 0.8654 & 1.2642 & 1.1237 & 0.9730 \\
\hline
\end{tabular}

Fuente: Elaborado por la División Agrícola Conjunta CEPAL/FAO sobre la base de CEPAL, 1983.

a El promedio para el conjunto de los sectores es igual a 1.

b Excluye combustibles y lubricantes y comercio.

América Latina (cuatro países): Relación entre los efectos directos e indirectos por unidad de demanda final entre el sector alimentario y el resto de los sectores (Porcentajes) $^{\mathrm{a}}$

\begin{tabular}{|c|c|c|c|c|c|c|c|c|}
\hline & \multicolumn{2}{|c|}{ Brasil } & \multicolumn{2}{|c|}{ Guatemala } & \multicolumn{2}{|c|}{ México } & \multicolumn{2}{|r|}{ Chile } \\
\hline & $\begin{array}{l}\text { Agricul- } \\
\text { tura }\end{array}$ & $\begin{array}{l}\text { Industria } \\
\text { alimentaria }\end{array}$ & $\begin{array}{l}\text { Agricul- } \\
\text { tura }\end{array}$ & $\begin{array}{c}\text { Industria } \\
\text { alimentaria }\end{array}$ & $\begin{array}{c}\text { Agricul- } \\
\text { tura }\end{array}$ & $\begin{array}{c}\text { Industria } \\
\text { alimentaria }\end{array}$ & $\begin{array}{c}\text { Agricul- } \\
\text { tura }\end{array}$ & $\begin{array}{l}\text { Industria } \\
\text { alimentaria }\end{array}$ \\
\hline Remuneraciones & 52.7 & 68.9 & 61.2 & 77.5 & 74.9 & 74.7 & 51.0 & 59.3 \\
\hline Excedente bruto & 136.8 & 122.4 & 136.1 & 91.8 & 130.7 & 123.3 & 170.1 & 130.9 \\
\hline Insumos importados & 22.6 & 62.5 & 55.6 & 216.5 & 22.2 & 65.1 & 55.2 & 119.1 \\
\hline Empleo & 309.8 & 127.1 & 460.0 & 180.0 & 648.3 & 319.0 & 207.5 & 102.5 \\
\hline Valor agregado & 104.7 & 102.3 & 105.4 & 85.9 & 104.3 & 101.9 & 108.2 & 96.5 \\
\hline Producción bruta & 82.5 & 117.2 & 92.5 & 134.1 & 88.9 & 129.9 & 98.0 & 122.4 \\
\hline
\end{tabular}

Fuente: Elaborado por la División Agrícola Conjunta CEPAL/FAO sobre la base de CEPAL, 1983.

a El cuadro registra el cuociente entre los efectos directos e indirectos por unidad de demanda final sobre la agricultura y la industria alimentaria respecto de los del resto de la economía; así por ejemplo, el coeficiente para las remuneraciones en Brasil fue de 0.1945 para la agricultura; de 0.2545 para la industria alimentaria y de 0.3691 para el resto: $(0.1945 / 0.3691)=(0.527 * 100)=52.7 ; \quad(0.2545 / 0.3691)$ $=(0.689 * 100)=68.9$ y así sucesivamente para las demás categorías.

res de fuerza de trabajo, tanto en la actividad agroindustrial propiamente tal como, sobre todo, a partir de la combinación de actividades agrícolas que; por estar integradas a un proceso de transformación industrial, permitirían el uso más intensivo de mano de obra por hectárea; y iii) la agroindustria puede convertirse en un elemento integrador u ordenador de la actividad primaria, facilitando su organización en las áreas que son su fuente de alimentación directa e indirecta, incluso en los casos en que ella esté reducida, por ejemplo, a plantas de desgrane y molienda. A este respec-

5 Muchos de los productos agrícolas pueden procesarse eficientemente en plantas cuyo costo oscilaba entre 1 y 3 millones de dólares de 1980, con la excepción de las destilerías y las plantas cerveceras, cuyo costo puede superar los 20 millones (CET, 1981, pp. 149-50, 158). to, el núcleo agroindustrial impone ritmos de trabajo, volúmenes de producción y niveles de calidad en sus fuentes de abastecimiento.

De particular relevancia es el potencial competitivo de la articulación entre la agricultura familiar y la agroindustria, tanto en la producción de alimentos como de productos de agroexportación, sobre todo en los casos en que la materia prima agrícola supone el empleo muy intensivo de mano de obra por hectárea, que no puede ser reemplazada eficientemente por la mecanización. El sustento teórico de dicho potencial competitivo radica en que, por las razones expuestas esquemáticamente (cuadro 1), el costo de inducir la producción de un determinado bien es inferior en las unidades familiares que en una unidad de tipo empresarial; la diferencia equivaldría, grosso modo, a la que hay entre la ganancia esperada por esta última para 
emprender dicha actividad y el excedente que requeriría la unidad familiar, por encima de lo necesario para sostener la familia y la unidad de producción. Esta consideración es particularmente importante en un contexto en que los generosos márgenes de utilidad de las primeras fases de desarrollo de determinados rubros empiezan a declinar y en que la competencia de costos se va agudizando en los mercados nacionales e internacionales.

La asociación entre la agroindustria y la pequeña producción resulta al parecer más prometedora en los casos de productos que suponen el uso intensivo de mano de obra; que son de alta perecibilidad, más que los granos y tubérculos que pueden obtenerse fácilmente en el mercado abierto; que tienen alto valor por unidad de volumen o de peso, de modo que los costos de transporte y de transacción tengan menor importancia relativa, y que pueden experimentar incrementos importantes de valor agregado en las fases posteriores a la cosecha, entre otros (Goldsmith, 1985 pp. 11-32).

Para que las potencialidades de la articulación puedan materializarse, la producción agrícola generada debe cumplir con los requisitos de calidad, homogeneidad y regularidad que la producción agroindustrial exige, sobre todo cuando se trata de productos para la exportación. Estas características no se dan espontáneamente en el sector de la agricultura familiar sino que suponen - como lo muestran los ejemplos exitosos al respecto- un proceso de organización y de capacitación de dichos productores, así como términos de relación que neutralicen el riesgo que invo- lucran las actividades distintas de la producción de autoconsumo y que aseguren cierta simetría en la distribución de los beneficios derivados de los incrementos de productividad.

Si las consideraciones sobre el potencial competitivo de la articulación entre la agricultura familiar y la agroindustria son válidas y si los atributos genéricos de los productos donde ésta aparece como más viable son los indicados, habrá que explorar el tipo de cadenas agroindustriales en que dicho potencial resulta más manifiesto, dadas las tendencias del desarrollo tecnológico y de la evolución de la demanda mundial de productos de base agrícola.

Entre los factores que han de considerarse para responder al interrogante anterior se mencionan los siguientes: i) la presencia o ausencia de economías de escala en la base agrícola proveedora de insumos; ii) el dinamismo de la demanda nacional e internacional de productos de la agroindustria considerada; iii) la importancia del insumo agrícola en el valor del producto final; y iv) la flexibilidad de la agroindustria en materia de escala y de localización.

La capacidad de la agroindustria de promover el progreso técnico en su entorno agrícola dependerá de la presencia de determinadas combinaciones de los factores indicados. Por otra parte, si a los objetivos del desarrollo de la agricultura competitiva se añaden los de la seguridad alimentaria, pueden hacerse también algunas consideraciones relativas a la importancia de los productos en la dieta (en función del porcentaje de calorías que aportan) o en el gasto alimentario de los sectores de menores ingresos.

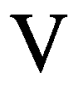

\section{Tipos de agroindustrias}

Como una primera aproximación a la elaboración de una tipología, empleando los criterios mencionados y teniendo como eje la capacidad de la agroindustria de promover el progreso técnico en sus articulaciones con su base agrícola, podemos distinguir cinco tipos de agroindustrias (cuadro 4).

1. Las agroindustrias básicas tradicionales, que corresponden a las cadenas centradas en los granos básicos o los tubérculos para consumo humano, se caracterizan por la baja elasticidad de la demanda; su gran heterogeneidad en la fase industrial; la presencia creciente de economías de escala en la producción primaria; y un comercio internacional dominado por un número reducido de grandes transnacionales, con escasa transparencia en sus operaciones.

Con excepción de algunas líneas de la cadena dominadas por agroindustrias concentradas (pastas) su capacidad de generar progreso técnico en la agricultura familiar es muy reducida.

2. Las agroindustrias básicas modernas se caracterizan por el gran dinamismo de su demanda; por un grado relativamente alto de concentración en el 
núcleo principal de la cadena; por la presencia de economías de escala en algunos de los insumos agrícolas (granos para alimentación animal y oleaginosos) y su relativa ausencia en otros (engorda de aves, remolacha azucarera, producción de lácteos, semillas). Su capacidad de impulsar el progreso técnico es relativamente alta, sobre todo en los casos en que no hay economías de escala significativas en la base primaria.

3. Las agroindustrias de productos diferenciados o de marca se caracterizan especialmente por el papel decisivo que tiene la propaganda en el dinamismo de la demanda; el peso de los insumos agrícolas en el producto final es generalmente muy bajo (papas fritas, bocadillos, derivados de cereales, gaseosas, y otros); el núcleo agroindustrial muestra, en general, un alto grado de concentración y su capacidad de generar progreso técnico en la base agrícola es muy baja, o quizá nula, dada la escasa importancia del insumo agrícola en el valor final del producto.

4. Las agroindustrias de agroexportación tradicionales. Cuando estas agroindustrias se basan en granos básicos (trigo, harina, arroz, maíz) se asemejan a las agroindustrias básicas tradicionales en cuanto a su capacidad de promover el progreso técnico; sin embargo, las exigencias de calidad y regularidad pueden redundar en una mayor capacidad potencial a ese respecto que la que poseen las agroindustrias de consumo interno. Por otra parte, muestran un grado ma- yor de concentración en el núcleo agroindustrial o agrocomercial y una homogeneidad mucho mayor en las unidades que componen dicho núcleo.

\section{Las agroindustrias de agroexportación nue-} vas o modernas Se concentran, entre otros, en productos hortofrutícolas, flores y esencias y, en general, en productos de alto valor agregado por unidad de peso. Se caracterizan por su alto dinamismo en la demanda internacional; por no presentar economías de escala significativas en la producción primaria, permitiendo una alta rentabilidad en unidades pequeñas, y por un alto grado de concentración, con algunas excepciones, en el núcleo agrocomercial $o$ agroindustrial. Tienen una gran capacidad potencial de generar progreso técnico con elevación de los niveles de vida en las áreas de pequeña producción.

De la tipología anterior (cuadro 4) -cuyo carácter meramente tentativo reiteramos- se desprende el siguiente ordenamiento de los rubros considerados, atendiendo a la importancia de su potencial generador de progreso técnico en la agricultura familiar:

$l^{\circ} \quad$ Los rubros de agroexportación moderna

$2^{\circ} \quad$ Los rubros básicos modernos

$3^{\circ} \quad$ Los rubros de agroexportación tradicional

$4^{\circ} \quad$ Los rubros básicos tradicionales

$5^{\circ}$ Los productos diferenciados o de marca.

Sin perjuicio de esta jerarquización, por consideraciones de seguridad alimentaria puede ser conveniente combinar rubros de agroexportación nuevos con rubros básicos tradicionales y/o de agroexporta-

CUADRO 4

Tipología de agroindustrias

\begin{tabular}{|c|c|c|c|c|c|c|}
\hline Tipo de agroindustrias & Dinamismo & $\begin{array}{c}\text { Grado de } \\
\text { concentración }\end{array}$ & $\begin{array}{c}\text { Escala en } \\
\text { base agrícola }\end{array}$ & $\begin{array}{l}\text { Peso en } \\
\text { la dieta }\end{array}$ & $\begin{array}{l}\text { Peso de la } \\
\text { propaganda }\end{array}$ & $\begin{array}{l}\text { Capacidad } \\
\text { de inducción }\end{array}$ \\
\hline $\begin{array}{l}\text { 1. Básicas } \\
\text { tradicionales }\end{array}$ & $\bar{l}$ & $-\uparrow$ & $++\uparrow$ & $\begin{array}{c}+++ \\
\downarrow\end{array}$ & $-\cdots$ & -- \\
\hline $\begin{array}{l}\text { 2. Básicas } \\
\text { modernas }\end{array}$ & +++ & $++\uparrow$ & $+?$ & $\begin{array}{r}++ \\
t\end{array}$ & -- & -- \\
\hline 3. Diferenciadas & +++ & $+++\uparrow$ & ++ & $-\uparrow$ & +++ & -- \\
\hline $\begin{array}{l}\text { 4. De agroexportación } \\
\text { tradicional }\end{array}$ & $\dddot{l}$ & ++ & $++\uparrow$ & & -- & $-?$ \\
\hline $\begin{array}{l}\text { 5. De agroexportación } \\
\text { moderna }\end{array}$ & $\stackrel{++}{t}$ & $++\uparrow$ & -- & & $-?$ & +++ \\
\hline
\end{tabular}

Notas:

-. - nulo

- muy bajo

- bajo

$\begin{array}{ll}+++ \text { decisivo } & \uparrow \text { creciente } \\ ++\quad \text { muy alto } & \downarrow \text { decreciente } \\ +\quad \text { alto } & \end{array}$

+ alto
? depende del caso 
ción tradicional: el esfuerzo por promover el progreso técnico en los primeros puede, por la vía del efecto demostración, traducirse en mejoras tecnológicas en los rubros de consumo básico.

\section{VI}

\section{Ventajas y riesgos para los participantes}

La agricultura de contrato, en sus diversas variantes, así como los acuerdos más informales entre pequeños productores y agroindustrias de distinto tamaño y forma de organización, no son un fenómeno nuevo, aunque en general han surgido sin que haya una política destinada a estimular su desarrollo y regular las relaciones entre los agentes. De dicha experiencia se derivan ventajas y problemas para ambas partes, las que se enumeran a continuación.

\section{a) Ventajas para la agroindustria}

Las siguientes serían las ventajas principales:

i) Traspasar a terceros los riesgos inherentes a la producción agrícola;

ii) eludir los problemas derivados de las relaciones salariales;

iii) evitar la caída en causales de expropiación contempladas en las leyes de la Reforma Agraria;

iv) evitar la inmovilización del capital en tierras;

v) acceder a tierras aptas para el cultivo de los insumos que requiere la agroindustria en áreas a las que únicamente es posible acceder mediante acuerdo con los productores en general o con los pequeños productores, si ésta es la forma de tenencia en dichas áreas;

vi) reducir los costos cuando la producción propia resulta más onerosa, optando por los pequeños productores cuando las empresas agrícolas demandan precios mayores, aun si se considera el incremento de los costos de transacción derivados de su abastecimiento por estos últimos;

vii) estímulos públicos o legislación que induzcan o imponga, respectivamente, la compra a pequeños productores.

\section{b) Riesgos para la agroindustria}

Entre los riesgos los más importantes son:

i) El incremento de los costos de transacción a medida que aumenta el número de proveedores (transporte, asistencia técnica, control de calidad, administración y otros);

ii) la complejidad de los contratos que incluyen, (para asegurar eficiencia) múltiples variables (cali- dad, oportunidad, precio) que son difíciles de regular y que se prestan a continuas controversias;

iii) la venta a terceros cuando el precio acordado es menor que el del mercado en el momento de la entrega;

iv) el desvío de los insumos entregados por la agroindustria a otros usos distintos de los acordados.

c) Ventajas para el pequeño productor:

Entre las ventajas figuran:

i) Mercado seguro y, si el contrato lo estipula, a precio preestablecido;

ii) asistencia técnica que le permite elevar la productividad por hectárea;

iii) incorporación de productos de mayor valor;

iv) mayor aprovechamiento de la mano de obra familiar, pues generalmente se trata de productos que suponen el empleo más intensivo de mano de obra por hectárea;

v) posibilidad de aplicar los nuevos conocimientos a productos tradicionales o a otros no incluidos en el convenio;

vi) en algunos casos, acceso a medios de producción (maquinarias o equipos) de propiedad de la agroindustria.

\section{d) Riesgos para el pequeño productor}

En general, la mayoría de los riesgos derivan de las posibilidades que pueda tener la agroindustria de manipular los términos de los acuerdos, sea porque los proveedores no dominan sus términos o porque éstos son lo suficientemente ambiguos como para permitir interpretaciones que, dependiendo del poder de regateo, se usan en favor de la agroindustria.

Los más corrientes son:

i) Manipulación de los estándares de calidad para regular los precios y las entregas;

ii) recepción tardía para reducir el precio;

iii) amarrar un contrato a otro menos conveniente para el productor cuando la empresa adquiere más de un producto;

iv) inducir al monocultivo con la dependencia y vulnerabilidad que de ello se deriva; 
v) deficiencias en la asistencia técnica cuyos efectos pasan a ser responsabilidad del productor y no de la empresa que la proporcionó;

vi) pagos atrasados o falta de claridad en las liquidaciones;

vii) favoritismos en la asignación de las fechas más favorables para plantar.
La capacidad de manipulación de la empresa es mayor cuando tiene una posición monopólica, cuando se autoabastece de una proporción importante del insumo agrícola, cuando los productores son monocultivadores de dicho insumo y éste no es de ciclo corto o cuando están endeudados con la empresa.

\section{VII}

\section{Consideraciones finales}

De lo señalado hasta aquí deriva una serie de consideraciones que pueden servir de base para diseñar una estrategia de modernización de la agricultura familiar que se apoye en el potencial generador de desarrollo tecnológico de la agroindustria. En términos resumidos éstas serían las siguientes.

$\square$ Una política de laissez faire, aun en un marco de equilibrios macroeconómicos razonables, es insuficiente para promover un proceso de modernización en la agricultura familiar y, por lo tanto, para insertarla en una dinámica de crecimiento con equidad.

Algunos núcleos agroindustriales o agrocomerciales poseen gran capacidad para impulsar el progreso técnico en su entorno agrícola, en general, y entre los pequeños agricultores, en particular.

$\square$ La capacidad del aparato público de asumir la tarea de promover el progreso técnico en la agricultura familiar no ha sido, en el pasado, muy exitosa; en las condiciones impuestas por la crisis del endeudamiento, ésta se ha visto aún más limitada, por lo que es necesario buscar fórmulas que eleven la eficiencia de la acción pública en las nuevas condiciones.

$\square$ La concertación entre el sector público y las agroindustrias $\mathrm{o}$ agrocomercios que tengan mayor capacidad de inducción de progreso técnico, sería el camino adecuado para materializar dicho potencial, con mucho mayor eficacia que la lograda por las iniciativas espontáneas.

Para aprovechar las potencialidades que encierra el fortalecimiento de los vínculos entre la agroindustria y la agricultura se requiere, entre otras cosas:

$\square$ Crear un marco institucional que garantice la transparencia y simetría en las relaciones entre los productores agrícolas y la agroindustria.

Establecer un conjunto de estímulos para que las agroindustrias seleccionadas en función de su potencialidad asuman las tareas de capacitar y transferir tecnología a los pequeños productores capaces de transformarse en proveedores estables de dichas agroindustrias. Esos estímulos deberán contemplar, entre otras cosas, la subvención a los mayores costos de transacción y de capacitación que significa la creación de dicha base de proveedores.

$\square$ Estimular la organización de los pequeños productores, buscando un grado razonable de homogeneidad entre los miembros y contemplando, además, la constitución de agroindustrias cooperativas o de sociedades mixtas con empresarios privados.

Para concluir, cabe destacar, a modo de advertencia, que el desarrollo agroindustrial no reemplaza al esfuerzo que es necesario hacer en el ámbito del desarrollo rural. Si bien la agroindustria coadyuva al desarrollo rural, para que su articulación con la actividad primaria manifieste sus reales potencialidades debe alcanzarse, como condición necesaria, un desarrollo rural efectivo. Es importante también destacar que parte importante de la agroindustria de la región opera con niveles de capacidad ociosa que en algunos casos son bastante elevados, constituyéndose en este sentido una especie de "barrera a la entrada" de nuevas iniciativas que pretendan desarrollarse en las áreas en que dicha capacidad ociosa está presente. Por último, la capacidad de absorción de empleo directa por parte de la agroindustria no es todo lo alta que se supone. En muchos casos, determinadas actividades agroindustriales suponen niveles de inversión por empleo generado, de magnitud igual y muchas veces superior a la de otras ramas industriales.

Hechas las observaciones anteriores, conviene reiterar que, si bien las articulaciones más evidentes se dan entre la agroindustria y la agricultura, la desconcentración de la industria en general y su "ruralización" como parte de una política más general de 
valorización del espacio rural, serían factores de gran potencialidad en la tarea de frenar el éxodo rural y elevar el empleo y el ingreso campesinos como lo muestra la experiencia de varios países europeos y de algunos países asiáticos de industrialización reciente (Ho, 1979).

\section{Bibliografia}

CEPAL (Comisión Económica para América Latina y el Caribe) (1983): Tablas de insumo-producto en América Latina, Cuadernos estadísticos de la CEPAL, $\mathrm{N}^{\circ} 7$ (E/CEPAL/G. 1227), Santiago de Chile.

(1990): Transformación productiva con equidad, (LC/ G.1601(SES.23/4)), Santiago de Chile.

CET (Centro de las Naciones Unidas sobre las Empresas Transnacionales) (1981): Transnational Corporations in Food and Beverage Processing, Nueva York. Publicación de las Naciones Unidas, $\mathrm{N}^{\mathbf{0}}$ de venta E.81.II.A.12.

Fajnzylber, Fernando (1989): Industrialización en América Latina: de la "caja negra" al "casillero vacio", Cuadernos de la CEPAL, $N^{\circ} 60$ (LC/G.1534/Rev. 1-P), Santiago de Chile. Publicación de las Naciones Unidas, $\mathrm{N}^{\circ}$ de venta S.89.II.G.5.

FAO (Organización de las Naciones Unidas para la Agricultura y la Alimentación) (1988): Potencialidades del desarrollo agrícola y rural en América Latina y el Caribe (LARC 88), Roma.

Goldsmith, Arthur (1985): The private sector and rural development: Can agribusiness help the small farmer?, World Development, vol. 13, No 10/11, Oxford, Reino Unido, Pergamon Press.

Ho, Samuel P.S. (1979): Descentralized industrialization and rural development: Evidence from Taiwan Economic Development and Cultural Change, vol. 28, $\mathrm{N}^{\circ} 1$., Chicago, Illinois, University of Chicago Press.

Johnston, Bruce F. y Peter Kilby (1975): Agriculture and Structural Transformation, Economic Strategies in Late-Developing Countries, Nueva York, Oxford University Press.

Schejtman, Alexander (1980): Economía campesina: lógica interna, articulación y persistencia, Revista de la CEPAL, No 11 , Santiago de Chile. Publicación de las Naciones Unidas, $\mathrm{N}^{\circ}$ de venta S.80.II.G.3. 